\title{
Declassified Intelligence Satellite Photographs
}

Recently declassified photographs from spy satellites are an important addition to the record of the Earth's land surface held by the U.S. Geological Survey (USGS).

More than 800,000 high-resolution photos taken between 1959 through 1972 were made available by Executive Order of the President. The collection is held at the USGS EROS Data Center, near Sioux Falls, S. Dak., and are offered for public sale. For some purposes in earth science studies, these photos extend the record of changes in the land surface another decade back in time from the advent of the Landsat earth-observing satellite program.

\section{Landsat Multi- spectral Scanner Image}

In the Cape Canaveral, Florida, image pair (at right), the Landsat MSS image (acquired March 1992) shows how agricultural use of a marshy region near Cape Canaveral has expanded since the declassified image was acquired (Mission 9059A, October 30, 1963). In the declassified image, the region is dissected by ponds and small stream channels. In the Landsat image, acquired more than 28 years later, many of the small streams have been modified by dams and reservoirs, a network of roads has been constructed in the area, and agricultural development has increased.

\section{Summary of Satellite Missions}

KH-1 Dates: June '59-Sep. '60 Ground Resolution: $25 \mathrm{ft}$ Notes: Single camera Frames: 1,432

KH-2 Dates: Oct. '60-Oct. '61 Ground Resolution: $25 \mathrm{ft}$ Notes: Single camera Frames: 7,246

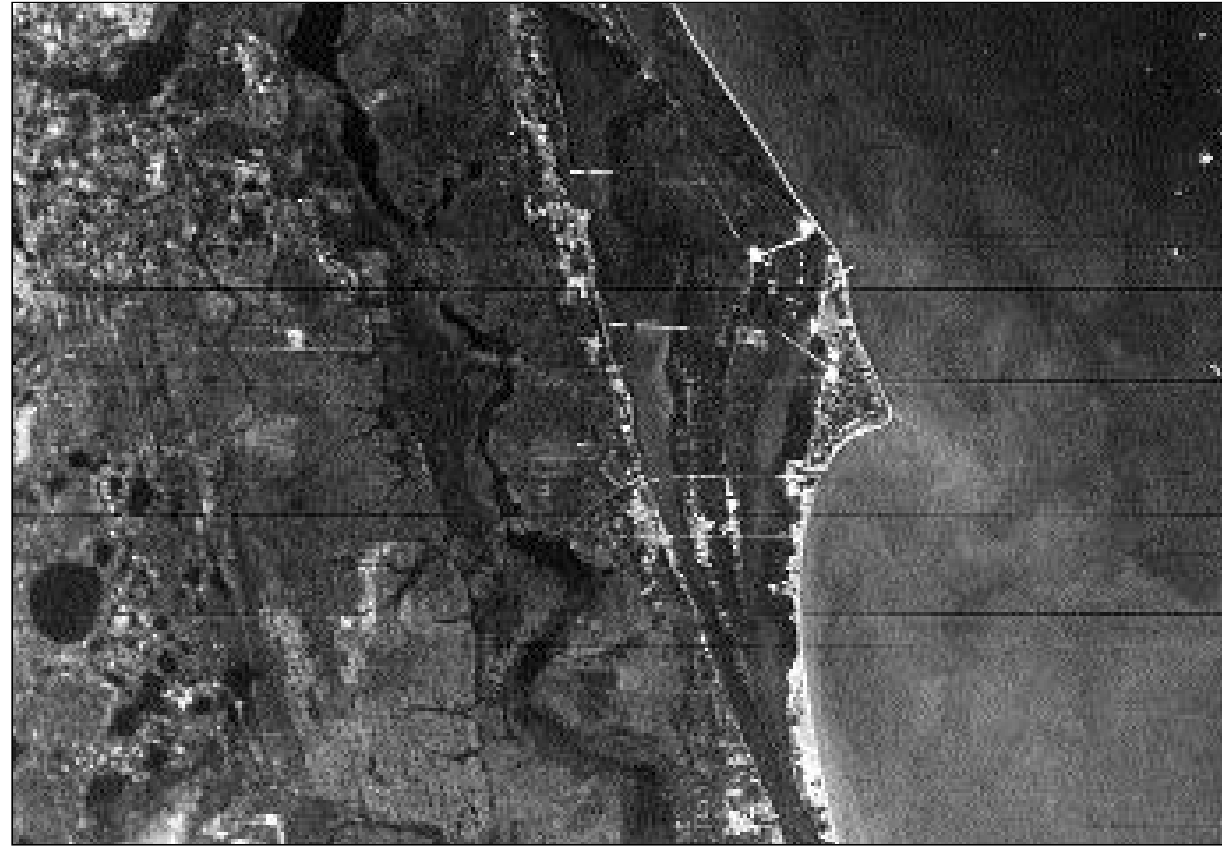

1963 declassified image over Cape Canaveral, Florida.

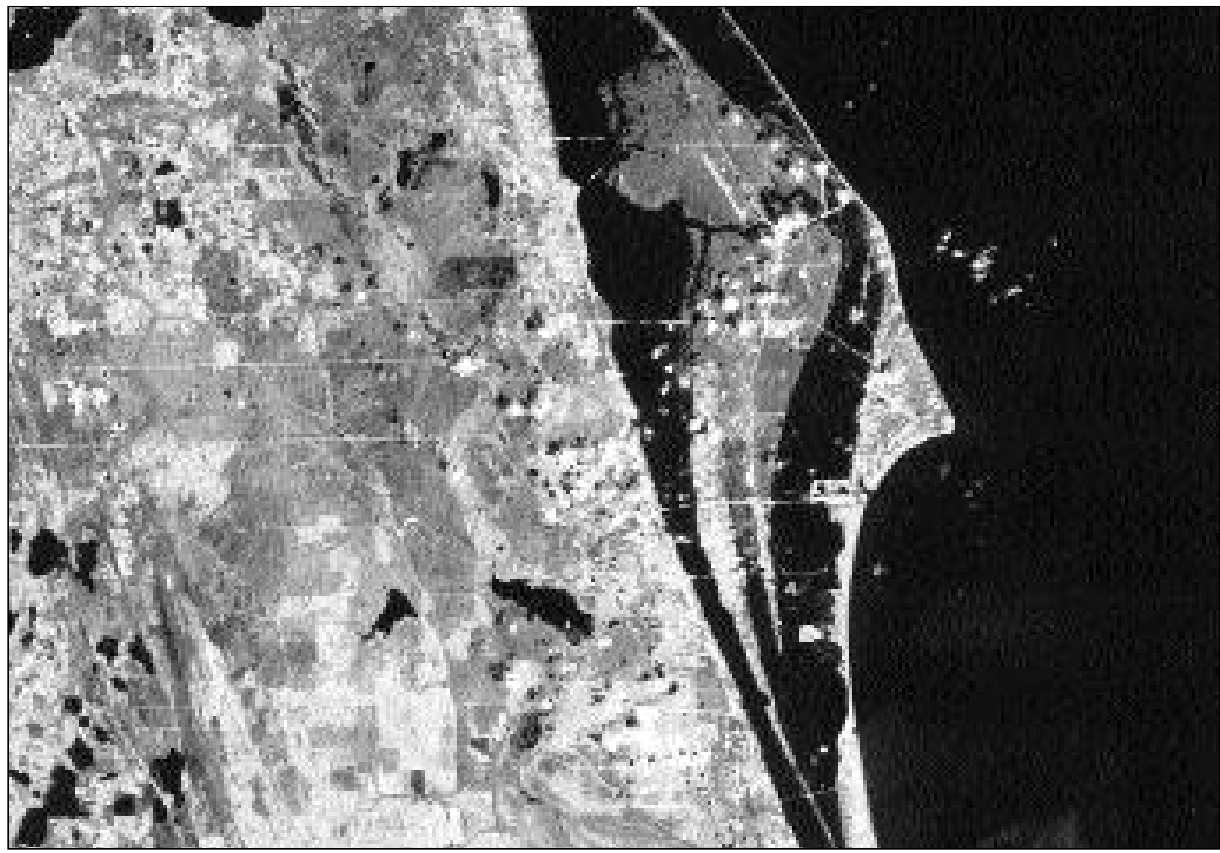

1992 Landsat image over Cape Canaveral, Florida.

KH-3 Dates: Aug. '61-Jan. '62 KH-4 Dates: Feb. '62-Dec. '63 Ground Resolution: $25 \mathrm{ft}$

Notes: Single camera Frames: 9,918
Ground Resolution: $25 \mathrm{ft}$

Notes: Two cameras Frames: 101,743 
KH-4A Dates: Aug '63.-Oct. '69

Ground Resolution: $9 \mathrm{ft}$

Notes: Two cameras

Frames: 517,688

KH-4B Dates: Sep. '67-May '72

Ground Resolution: $6 \mathrm{ft}$

Notes: Two cameras

Frames: 188,526

KH-5 Dates: Feb. '61-Aug. '64

Ground Resolution: $460 \mathrm{ft}$

Notes: Global coverage, mapping camera

Frames: 38,578

KH-6 Dates: July '63

Ground Resolution: $6 \mathrm{ft}$

Notes: Panoramic camera

Frames: $<910$

\section{Available Products}

Products available from the USGS include contact-scale, black-and-white, positive film, negative film, and paper prints. In addition, custom enlargements are available if customers purchase a contact-scale paper print and annotate on that print the area to be enlarged and the amount of enlargement. The National Archives and Records Administration holds the original negatives as well as technical mission-related documents that include the orbit parameters for each mission.

\section{World Wide Web Access}

An online description of this photographic collection is available on a USGS World Wide Web server. The Web address for this document is

<URL: http://edcwww.cr.usgs.gov/ glis/hyper/guide/disp>.

\section{Internet Catalog and} Browse

An Internet catalog and image browse capability for the entire collection is available, at no charge, on the USGS Global Land Information System (GLIS).

GLIS can be accessed any one of three ways:

For text-only access:

telnet glis.cr.usgs.gov

For X Windows graphics access:

telnet xglis.cr.usgs.gov

For Web access:

<URL: http://edcwww.cr.usgs.gov/ webglis/ >

\section{Information}

For information related to image products from this collection, contact:

Earth Science Information Center

EROS Data Center

Sioux Falls, SD 57198

Telephone: 605-594-6151

Fax: 605-594-6589

E-mail: custserv@usgs.gov

For information related to mission

documents, contact:

National Archives and Records

Administration

Cartographic and Architectural Branch

(NNSC)

8601 Adelphi Rd.

College Park, MD 20740-6001

Telephone: 301-713-7030

Fax: 301-713-7488

E-mail: carto@arch2.nara.gov
For information on other USGS products and services, call 1-800-USA-MAPS, or receive information from the EARTHFAX fax-on-demand system, which is available 24 hours a day at 703-648-4888.

Please visit the USGS home page at <URL: http://www.usgs.gov/>. 